\title{
Chapter 2 \\ Disorderly Identities: University Rankings and the Re-ordering of the Academic Mind
}

\author{
Jon Nixon
}

\begin{abstract}
This chapter focuses on the use of university rankings as a means of ostensibly achieving increased transparency and covertly introducing a competitive market which has impacted on the sector as a whole, on institutions, and on individuals. The systemic characteristics of this new and now increasingly dominant market-driven order are outlined, followed by an exposition of how that order has impacted on the mind-set of academic practitioners by defining the norms of academic professionalism and academic practice. A new kind of orderliness now circumscribes and defines what it means to be an academic. Some of the emergent but pressing alternatives to this identity-kit of orderliness are suggested: disorderly identities that transgress the spatial boundaries of the dominant order, challenge its control of the chronology of that order, and begin to constitute participative and non-hierarchical foci of pedagogical action and participative research.
\end{abstract}

\section{Introduction}

University rankings are now a world-wide phenomenon. Used ostensibly as a means of achieving increased transparency, and covertly as a way of introducing a competitive market into higher education, the various ranking exercises have had an immense impact on the higher education sector as a whole, on individual institutions, and on professional career paths. They have been instrumental in defining 'the world class university' and establishing the benchmarks for academic preferment. Within the UK, the Research Assessment Exercise (RAE)_now re-branded the Research Excellence Framework (REF)—-has in effect created a new and increasingly dominant order. This chapter discusses the systemic characteristics of that order and explains how it has impacted on the mind-set of academic practitioners by

J. Nixon ( $₫)$
Middlesex University, London, UK

The Education University of Hong Kong, Ting Kok, Hong Kong

(C) The Author(s) 2020

S. Rider et al. (eds.), World Class Universities, Evaluating Education:

Normative Systems and Institutional Practices,

https://doi.org/10.1007/978-981-15-7598-3_2 
defining the norms of academic professionalism and academic practice. A new kind of orderliness now circumscribes and defines what it means to be an academic.

I focus on one policy in particular: namely, the use of university rankings as a means of ostensibly achieving increased transparency and covertly introducing a competitive market which has impacted—in my view deleteriously — on the sector as a whole, on institutions, and on individuals. I begin by outlining the systemic characteristics of this new and now increasingly dominant market-driven order. I then show how that order has impacted on the mind-set of academic practitioners by defining the norms of academic professionalism and academic practice. Finally, I suggest some of the emergent but pressing alternatives to this identity-kit of orderliness: disorderly identities that transgress the spatial boundaries of the dominant order, challenge its control of the chronology of that order, and begin to constitute participative and non-hierarchical foci of pedagogical action and participative research.

\section{The Shaping of the Sector}

Over the last 30 years the ranking of universities according to their research output has shaped the UK university sector as a whole, had a profound impact on individual institutions, and been a major determinant of academic career trajectories. It has created a new ordering of institutions, which has in turn created a new order of academic prestige and status. Of course this orderliness has always been an insistent and pressing subtext of the UK higher education system, but the increasing influence of ranking exercises - and, in the case of the UK, the direct linking of one such exercise to government funding streams - has ensured that the increasing stratification of the university sector has kept pace with what until the financial crisis of 2008 was an exponential increase in its expansion. University rankings are continuing to shape not only the institutional landscape of the university sector, but also the mental landscape of its academic practitioners.

The mechanism by which the research ranking of UK universities is achieved was initially termed $\mathrm{RAE}^{1}$, but has now been modified and renamed the REF. The RAE was conducted in 1986, 1989, 1992, 1996, 2001 and 2008. The most recent REF exercise took place in 2014, and the next REF exercise is scheduled for $2021{ }^{2}$

\footnotetext{
${ }^{1}$ The 1986 RAE predated the UK Times Higher Educational Supplement league table, which was first published in 1993. The inception of the RAE also predated the Shanghai Jiao Tong University league table, which was first published in 2003. Because it set precedence, the RAE-now the REF - continues to exert considerable influence not only within the UK but internationally. Indeed, the RAE might be seen as having served as a model for the later development of global rankings.

${ }^{2}$ Although the assessment criteria for both the RAE and the REF have remained much the same, with a continuing emphasis on 'originality', 'rigour' and 'significance', the REF has placed a renewed emphasis on 'impact'. See, for example, Watermeyer (2016), Watermeyer and Hedgecoe (2016) and Wilkinson (2017).
} 
The prime purpose of the RAE - now the REF - is to provide a basis for the allocation of government funding to higher education institutions. Each university is invited to submit as its entry a profile of research outputs represented by academics' selected publications (up to four publications per academic). University departments are then ranked according to these profiles through a process of peer review (i.e. subject panels of expert academics). It is these rankings that determine the allocation of research funding each university receives.

Although presented as a means of encouraging research excellence across the higher education sector and of providing a differentiated system with the capacity to cater for diverse student needs, the exercise has had a stultifying effect by conferring on a small segment of that system the status and prestige of super-elite institutions and relegating all other institutions to second and third class status-and, in some cases, putting at risk their very survival. As a funding mechanism the erstwhile RAE and the current REF have, therefore, served to reproduce the deep structural inequalities across the sector-inequalities that, in turn, reinforce the social and economic inequalities across British society as a whole.

Moreover, this exercise in competitive ranking has been undertaken with the cooperation of academics without whom the peer review process would have been inoperable. Professional status has been accorded to those academics appointed to the various subject panels with responsibility for overseeing the assessment of particular units of assessment, while appointments to senior academic posts have been heavily influenced by applicants' potential rating in the research assessment stakes. Indeed, some of those who have been most vociferous in their condemnation of the research assessment process have been its greatest beneficiaries in respect of professional promotion and academic prestige. A ranking exercise that is continually defended as exemplary on account of its rigorous peer-reviewing processes would be impossible to implement were it not for the active involvement of those academic peers who chair and sit on its panels, occupy chairs in universities that disproportionately benefit from the results of the exercise, and spend a considerable amount of time preparing their departmental submissions at each point in the reporting process.

Academic identity is now bound into this new order. It is almost impossible to opt out given what is at stake - not just personally and professionally, but institutionally. The stakes are high: increased government funding, increased and enhanced staffing levels, more research students, enhanced facilities and resources, higher national and international profile, etc. Not to compete for these stakes appears to be at best self-defeating and at worst plain perverse: to be 'professional' is to enter wholeheartedly into the game; to stay on the sidelines is to be 'unprofessional'. For anyone who questions the premises upon which the competitive game is being played the space for maneuverability is highly restricted. The orderly identity denotes 'professionalism' and is commensurate with professional advancement and institutional loyalty. It would appear-within the current UK context- to be the only identity available. 


\section{The Established Order}

It is necessary to understand something of the history of higher education within the UK in order to appreciate why the RAE was deemed necessary and why it has impacted-and through the REF continues to impact-so heavily on the selfidentity of academics. The post-2008 recession has revealed the ever-widening gap between the welfare dream of the post-WWII settlement and its pragmatic realisation in the funding policies over the ensuing period. One of the unavoidable questions facing policy makers over the last 50 years has been how to manage their economies in a period of rapid globalisation and technological expansion. Crucial to any viable policy response to this question has been the development of a workforce with the necessary skills and understandings to face the challenges of late capitalism. The expansion of higher education was generally assumed to be a necessary precondition of an upwardly mobile and endlessly affluent society: universities were - unwittingly or otherwise - taking up a position in what has turned out to be an increasingly uneasy place between dream and reality, promise and fulfilment, consumption and cost.

The expansionist trend has been particularly pronounced in the UK and US. In the US, for example, 'between 1950 and 2000, the number of degree granting institutions more than doubled, from 1851 to 4084 [...] with total enrolment increasing from 2.6 million to 14.8 million students, more than fivefold in the fifty years' (Lazerson 2010, p. 14). The Netherlands, too, had seen student numbers rise steadily from approximately 50,000 in 1950 to approximately 500,000 in 2006 (Ritzen 2010 , p. 162). Tony Judt, in his history of post-WWII Europe, highlights the rapidity of that expansion across post-WWII Europe:

By the end of the 1960s, one young person in seven in Italy was attending university (compared to one in twenty ten years before). In Belgium the figure was one in six. In West Germany, where there had been 108,000 students in 1950, there were nearly 400,000 by the end of the Sixties. In France, by 1967, there were as many university students as there had been lycéen in 1956. All over Europe there were vastly more students than ever before. (Judt 2010, p. 394)

More recently other national regions have sought to increase educational opportunity at a bewildering pace: Canada, China, Japan, Russia, Singapore to name but a few. That expansion has had a huge global impact and has not come cheap. Responses to the soaring costs varied across regions. Jozef Ritzen documents what he terms 'the financial suffocation of European universities' (Ritzen 2010, pp. 133-156). In the US, on the other hand, annual expenditure for higher education went from $\$ 2.2$ billion in 1950 to $\$ 134.6$ billion in 1990 (National Center for Education Statistics 2008, Table 187, quoted in Lazerson 2010, p. 14). Where expansion has been matched by expenditure it has been justified on the grounds that universities provide personal advancement and national competitiveness. For the individual, universities were seen as the necessary route to the old and new professions; and, for the state, they provided the resources necessary for keeping ahead in the global markets. 
The crucial policy issue was - and is - how, and on what basis, to fund what was considered to be not only a vital but an essential expansion of the university sector. Responses to this policy issue invariably involved, on all sides of the political spectrum and across the globe, an emphasis on increased privatisation and increased profitability. The economic liberalisation that characterised the last two decades of the twentieth Century and the early years of the twenty-first Century did not in itself signal the fall of the welfare state, notwithstanding the best efforts of many of its economic and political theorists. It did, however, illustrate what Judt (2010, p. 558) has termed 'a seismic shift in the allocation of resources and initiative from public to private sectors'. What that shift from public to private occasioned was a new order based on managerial efficiency, cost effectiveness, and competition as a perceived driver of quality.

University rankings have become an increasingly important element within this now well established order. Marvin Lazerson (2010, p. 84) pointed out that '[s]ince the 1980s published rankings of colleges and universities have intensified the competition, in ways similar to various consumer reports on the quality of every item that is available for sale'. Within the UK the older universities have almost permanent and undisputed occupancy of the premier league; the post-1992 universities are well represented across the broad span of second league institutions; and the bottom league is occupied almost entirely by institutions that have gained university status more recently. What we see are levels of institutional sedimentation that provide the bases for structural inequalities that define, restrict and control the horizons of expectation and possibility. Competition between and within universities does not foster equity. It creates winners and losers.

Universities are now the cornerstone of this competitive order. They sustain a large part of what Sheldon S. Wolin in Democracy Incorporated termed 'a loyal intelligentsia'. 'Through a combination of governmental contracts, corporate and foundation funds, joint projects involving university and corporate researchers, and wealthy individual donors, universities (especially so-called research universities), intellectuals, scholars, and researchers have', he argues, 'been seamlessly integrated into the system'. Universities — and those who work within them-have become, as he puts it, 'self-pacifying' (Wolin 2010, p. 68). We pacify ourselves though our acquiescence to a system the underlying principle of which is self-interest.

\section{The Rankings Mind-Set}

The RAE would have been impossible to implement — as will the REF — without the cooperation and collusion of professional academics. UK academics have consistently collaborated in a system that stratifies institutions by judging them all according to a common yardstick. Of course, universities are judged by other yardsticks-for example, teaching excellence and student satisfaction-but, within the UK, research output has over the last 25 years become the prime measure of institutional and academic prestige. The UK higher education sector is thus at once homogenised and 
deeply stratified within an institutional hierarchy at the apex of which are a small number of research-led institutions fiercely competing for research funds, academic prestige, and high profile staff who are deemed capable of bringing in those funds and adding to that prestige.

The sector is also locked into a treadmill of academic production. Since the accounting system operates according to specific census points, research plans develop according to that timescale. It is imperative that research outputs are published within that time scale in order for them to 'count' in the overall assessment. Again, this both stratifies and homogenises institutions-and professional practices-across the UK higher education sector. They are at once wrapped into a common timeframe of accountability, while having vastly different resources with which to meet the accountability requirements. As each census point approaches the job market intensifies as institutions vie for the most prestigious and research-active staff and the pressure to publish in the top-rated journals mounts as those journals struggle to process the back-log of submissions. The effect on institutional systems and on academic cultures is dysfunctional in its erosion of collegiality and its imposition of bureaucratic frameworks.

The complex balance of priorities that characterises higher education is thereby skewed towards the production of research outcomes published in what are deemed to be the most prestigious academic journals. This affects the morale and motivation of academic staff, for whom the complex balancing of priorities is a defining feature of their academic professionalism. Referring specifically to the RAE, John K. Walton has argued that 'these deceptively simple evaluation systems are convenient for managers, who can use them to bully academics into publishing in the "right" journals; while academics in their turn are tempted to follow "hot" topics which generate citations and discouraged (or even forbidden) from performing necessary but less visible roles' (Walton 2011, p. 22). Similarly, Michael Bailey highlights the extent to which 'the pressure to perform well in the RAE has resulted in academics being subject to ever-increasing layers of micromanagement and performance indicators whose logic are more corporate than they are academic' (2011, p. 96).

The negative impact of RAE 2008 was also highlighted in a survey commissioned by the British Educational Research Association (BERA) and the Universities Council for the Education of Teachers (UCET). The ensuing report analysed the influences of the RAE on departments of education in 30 institutions. It found that a significant proportion of the staff surveyed 'reported negative impacts on their morale and motivation, on the quality, focus and breadth of their research publications, and more generally on their career development opportunities'. They also 'reported a sense of struggling to work and develop in what they described as a negative work climate, and of being hindered in their engagement, at a good level of quality, in other academic and academic-related activities, in particular in teaching' (BERA and UCET 2010, pp. 6-7).

This sense of the RAE having detracted from the quality of other academicrelated activities — and, in particular, from the quality of teaching — is reinforced by the findings of another survey conducted by the UK Open University Centre for Higher Education Research and Information. It found that between 1992 and 2007 
there had been a decline in the number of hours UK academics from across subject areas reported spending on teaching and an increase in the amount of time they reported spending on research. The proportion of academics that reported a primary interest in teaching had also decreased since 1992, whilst the percentage of staff claiming a primary interest in research rose by $9 \%$. Moreover, far fewer academics in the UK reported a primary interest in teaching compared with their international counterparts, with the UK lagging far behind China, South Africa and the USA. Although the authors of the report did not attribute this trend directly to the RAE, it is difficult not to infer a connection given the strong influence of the RAE in the period from 1992 to 2007 (See Universities UK 2008).

Not only has the RAE impacted negatively on teaching quality — by skewing the institutional priorities towards the production of research-but some would argue that it has also had a deleterious effect on the quality of the research produced. The BERA/UCET review, previously referred to, found that, "while productivity may have increased, outputs were seen as not only of questionable quality (rushed, rehashed, salami-slicing, etc.), but also skewed towards particular formats, audiences, and outlets (mainstream journals, rather than professional publications and books)' (BERA and UCET 2010, p. 31). Indeed, the extent to which RAE 2008 did in fact judge research quality is open to question. With over 200,000 outputs submitted as part of the 2008 exercise, it was not possible for panel members to read through each and every article. Consequently, panel members had to rely on proxy measures of quality, such as the supposed prestige of the journal in which a particular article had been published or even the reputation and/or professional standing of the author.

Institutions of higher education within the UK are increasingly homogeneous in their orientation towards a research agenda that has been shaped by the RAE and REF and increasingly stratified in respect of that agenda. Moreover, the 'winners' in the RAE stakes are inevitably on an upwardly mobile spiral, while the 'losers' are on an equally inevitable downward trajectory. The only discernible movement is among those institutions whose ranking places them in the middle ground. The 'winners' not only receive the lion's share of the public funding available through the RAE, but are best placed to attract funding from non-government sources and particularly from the private sector. Thus, an important aspect of the 'ideal type'towards which the RAE and REF nudge institutions of higher education-is its appeal to private interests.

The institutional drift carries in its wake an academic drift towards an 'ideal type' of academic identity: the system is premised on the assumption that, if every university craves to be a little Harvard, then a significant proportion of academics yearn to be tenured professors at that top-rated institution - or at the next best down the road. Many argue that this is in the interests of excellence, but in many ways it plays against the excellence of those institutions that are not at the top of the hierarchy - and, as the hierarchy deepens and sharpens, the proportion of those institutions that lose out increases and is increasingly reflected in the allocation of funding. Just as institutions are pulled towards uniformity, so individuals are pulled towards conformity. 
Academic identity becomes increasingly orderly: increasingly ordered according to the rules of the game determined by the ranking exercises and the prominence given to these rankings by the commercial press and funding agencies (including government) — and by the university sector itself. Ranking becomes a mind-set.

\section{Exquisite Tensions}

Peter Scott (2011) has noted: "Altruism no longer applies outside narrowing "tribes" of universities. Russell Group universities ${ }^{3}$ are beginning to choose only referees from other Russell Group universities on appointment and promotion committees, or as external examiners. Other "tribes" also favour their own (or, if they go outside, trade up_-but hardly ever down).' If these habits become routine, he argues, 'everyone will be a loser- "top" universities and ex-polytechnics alike-just as both rich and poor suffer in unequal societies'.

The kind of tribalism that Scott sees as characterising the UK higher education sector is clearly detrimental to the collegial well-being of universities and as such impacts adversely on their institutional effectiveness. At the level of academic practice, this lack of well-being is experienced as a clash of professional priorities and as a generalised sense of not being able to meet competing and sometimes conflicting requirements: the most obvious being the competing - and sometimes conflicting - demands of both teaching and research excellence. 'At the meso level,' as Lew Zipin and Marie Brennan (2012, p. 256) argue, 'managerial offices tend to simplify complexities, rather than come to grips with them; while, on the other hand, at the micro level, varied locations of university action cannot avoid grappling with new ways and degrees of real complexity'. The result is what Zipin and Brennan call 'a deep and exquisite tension' (original emphasis) that generates a vast range and complexity of competing claims thereby eroding any sense of shared institutional purpose.

Looking beyond the UK to the wider context, the focus on global university rankings is occasioning a more extensive drift towards international conformity. Anthony B. L. Cheung (2012, p. 102) notes a 'longstanding concern from some universities and academics that, with the reliance on international benchmarks developed by the USA and Western Europe, research in the humanities and social sciences of local significance has been increasingly marginalised'. The pull, in other words, is towards a notion of research excellence that is narrowly defined with regard to US, and to some extent UK, criteria - and that, as a consequence, fails to recognise any 'local significance' that falls outside that definition. Here the 'deep and exquisite tension' results from the global rankings restricting and diminishing the international diversity of universities world-wide.

\footnotetext{
${ }^{3}$ The Russell Group is a grouping of 20 UK universities that together receive two thirds of research and contract funding in the UK. It was established in 1994 to promote their collective interests.
} 
Simon Head has observed that ' $[w]$ ith the recession eating away at the budgets of universities on both sides of the Atlantic, the times are not propitious for those hoping to liberate scholarship and teaching from harmful managerial schemes'. Such liberation, he argues, would require 'a stronger and better-organized resistance on the part of the academy itself than we have seen so far' (Head 2011, p. 64). It would certainly involve among other things a new academic professionalism and a new sense of academic identity. It is difficult to see how the "harmful managerial schemes' —of which university rankings are a component element—can be resisted without the refusal of academic workers to collude in their implementation. New forms of collaborative endeavour - professional, institutional, and sector-wide-are required to provide collective solutions to what are essentially collective problems.

Any such search for solutions would require an acknowledgement by the sector as a whole that university rankings are part of a collective problem that can only be addressed collectively; and any such acknowledgement would constitute a disruption of the order by challenging its underlying assumptions: namely, that competition necessarily drives up quality, that markets are invariably beneficial, and that productivity must lead to profitability. Any such disruption would, in turn, require a disorderly academic presence - a pre-emergent identity — driven by discontent with the 'exquisite tension' implicit in the established order: what William Morris, in a lecture entitled 'The hopes of civilization' given to the Hammersmith Branch of the Socialist League in 1885, called 'the holy flame of discontent' (See Morris 2004, p. 321).

\section{Disorderly Identities}

The kinds of emergent—or pre-emergent—disorderly identities I am thinking of manifest themselves in activity that by disrupting the dominant order insists upon the possibility of new beginnings. Of course, not all such activity points to new ways forward: some may be deeply reactionary and simply motivated by a desire to return to 'the good old days', while others may be merely a novel re-branding of some aspects of the established order.

Raymond Williams, writing about the nature of cultural formation referred to these elements as 'emergent', 'residual' and 'dominant', and emphasised the difficulty and importance of distinguishing between them:

By 'emergent' I mean, first, that new meanings and values, new practices, new relationships and kinds of relationship are continually being created. But it is exceptionally difficult to distinguish between those which are really elements of some new phase of the dominant culture $[\ldots]$ and those which are substantially alternative or oppositional to it: emergent in the strict sense, rather than merely novel. (Williams 1977, p. 123)

It is worth bearing these distinctions in mind when considering the plethora of socalled initiatives that claim to be radical and progressive, but turn out to be recycled versions of the same old tired and often regressive policies that are designed to give 
an impression of innovation while maintaining the status quo-the REF being a case in point since it is indistinguishable in its underlying purposes from the RAE which it supersedes.

Nevertheless, it is possible to distinguish genuinely emergent elements, and Williams' analysis is again helpful in enabling us to do so:

What matters, finally, in understanding emergent culture $[\ldots]$ is that it is never only a matter of immediate practice; indeed it depends crucially on finding new forms or adaptations of form. Again and again what we have to observe is in effect a pre-emergence, active and pressing but not yet fully articulated, rather than the evident emergence which could be more confidently named. (Williams 1977, p. 126, original emphasis)

Tactically this is an important point, since one of the ploys of reactionary rhetoric has always been to assert that unless one can confidently name one's alternatives one has no right to criticise. ${ }^{4}$ Williams reminds us that in order to gain a critical purchase we must on occasion speak from a position that is as yet undefined or only partially defined and from within an identity that is as yet unnamed or named only in deficit terms. Such is the case with what I am terming disorderly identities, which, although oppositional, are oriented towards an emergent or pre-emergent order discernible in the opportunities for new forms of inter-connectivity, new ways of using one's own and others' time creatively, and new modes of cooperation and collaboration: opportunities that can only emerge through the disruption to existing sectoral boundaries, bureaucratic time-frames, and institutional hierarchies.

\section{Disrupting Boundaries}

The academic workplace is heavily bounded institutionally, professionally and epistemologically. Moreover, the boundaries denote highly contested territories: the university sector as a whole defends its patch against other sectors in the struggle for public and private funding; institutions fiercely defend their institutional autonomy and their particular market niche-and, also, their competitive edge if they are fortunate enough to be able to claim it; academics defend-with equal ferocity-the status of their particular group and their individual status within that group and the prestige that goes with it; disciplines and fields of study hedge themselves round with professional associations, learned journals and a seeming endless stream of academic conferences, seminars and symposia. Breaking down these boundariesor transforming them into fuzzier and more permeable borders-does not necessarily break up the competition and exclusivity by which they are maintained. Indeed, it may compound the problem of specialisation by spawning and ever-increasing number of exclusive sub-fields. But it can make the break-up of boundaries more likely, and, in so doing, hold out the possibility of increased inter-connectivity

\footnotetext{
${ }^{4} \mathrm{Hirschman}$ (1991) provides a witty and ironic analysis of the uses of reactionary rhetoric to deny the validity of legitimate criticism.
} 
across institutions, between academic workers, and among different disciplines and fields of study. ${ }^{5}$

\section{Disrupting Time-Frames}

'As gravity bends light, so power bends time', writes Christopher Clark (2018): 'time is not a neutral, universal substance [...] but a contingent cultural construction whose shape, structure, and texture have varied' (pp. 1, 4). As experienced by academic workers, time is almost entirely framed by institutional requirements. Of course, all organisations need agreed time-frames in order to ensure the fulfilment of complex tasks requiring individual and collective effort. However, time has now become one of the prime tools of management: external agencies impose deadlines on universities, which then pass a foreshortened version of those deadlines down the line to department heads, who in turn impose still tighter deadlines on those on the front line of 'delivery'. Complexity intensifies and gains pace as it is passed down the system (in the form of what, as noted above, Zipin and Brennan term 'a deep and exquisite tension'). The apocalyptic endpoint of this intensification of speed and complexity is - to mix metaphor and cliché-an organisational dance macabre within which the only observable activity is akin to headless chickens chasing their tails. To disrupt the dance is deemed to be 'unprofessional': a clear sign that one has distanced oneself from the corporate endeavour that represents university life and begun to join the ranks of the shirkers and skivers. Yet the disruption of the dance is essential if the organic time of academic work - the time to read and re-read, to research and think, to teach and mentor, and to write and re-write-is to be preserved and valued. It is only through the creative use of time that academic work becomes creative. ${ }^{6}$

\section{Disrupting Hierarchies}

Despite much academic rhetoric extolling democratic participation and distributed leadership, universities in the UK remain deeply and complicatedly hierarchical in both their management and governance. Moreover, the various hierarchies of seniority, status and prestige - each of which may be mystifying in its opacity-often collide in the course of everyday interaction as well as in the process of more formal

\footnotetext{
${ }^{5}$ The debate on cross-disciplinary, inter-disciplinary and transdisciplinary pedagogic practice and curriculum theory is relevant in this context. See, for example, the various contributions to Gibbs (2017).

${ }^{6}$ For differing perspectives on the conceptualisation and organisation of time in higher education, see: Alhadeff-Jones (2017), Berg and Seeber (2016), Gibbs et al. (2014), Rider (2016) and Vostal (2016).
} 
decision making. The huge disparity in contractual arrangements and conditions of service-with, for example, strict confidentiality relating to top professorial salaries and an increasing reliance on part-time staff and staff on fixed-term contacts-further complicates the culture of academic workplaces. With many vice chancellors and principals of institutions of higher education within the UK now on salaries well in excess of $£ 300,000$ a year, and some professors in some fields drawing both a hefty academic salary and a professional salary from other sources-and with women under-represented in the higher echelons of academia-universities have become extremely unequal workplaces. The potential for genuine cooperation and collaboration in such circumstances is extremely limited. Nevertheless, attempts to disrupt this force field of overt and covert hierarchies and establish small spaces for working together collectively — and against the grain of the structural inequalities inherent in the institution-do at least begin to model what collaborative practice and cooperative ways of thinking together might look like. ${ }^{7}$

\section{Conclusion}

Although university ranking exercises such as the RAE and REF locate institutions, departments and/or individuals on a scale, they are in effect zero-sum exchanges in which one institution's or individual's gain becomes another's loss. That in turn becomes a mind-set which shapes academic identities and institutional cultures by prioritising competition over cooperation. What Richard Sennett (2012, pp. 65-95) calls 'the fragile balance' between competition and cooperation - the give and take of human exchange-is thereby destroyed. Unlike differentiating exchanges that recognise different contributions and encourage cooperation and collaborative endeavour, zero-sum exchanges recognise only winners and losers. Within the UK university sector this prioritising of competition over cooperation has resulted in sectoral fragmentation, institutional stratification and professional atomisation. ${ }^{8}$ It is only at precise points of interconnectivity, creative work and cooperative practice that we can begin to develop alternative notions of what it means to be an academic - and thereby counter the competitive culture that currently dominates the higher education sector and point the way forward to a new kind of 'world class university'.

\footnotetext{
${ }^{7}$ I develop this theme more fully — and more broadly in relation to the structural inequalities within the higher education sector and the contested notion of higher education as a public good-in Nixon $(2011,2015)$.

${ }^{8}$ See Nixon (2008, pp. 16-24) for a fuller discussion of this process of fragmentation, stratification and atomisation.
} 


\section{References}

Alhadeff-Jones, M. (Ed.). (2017). Time and the rhythms of emancipatory education: Rethinking the temporal complexity of self and society. London: Routledge.

Bailey, M. (2011). The academic as truth-teller. In M. Bailey \& D. Freedman (Eds.), The assault on Universities: A manifesto for resistance (pp. 91-102). London: Pluto Press.

BERA and UCET. (2010). The BERA/UCET review of the impacts of RAE 2008 on education research in UK higher education institutions. London: BERA.

Berg, M., \& Seeber, B. K. (2016). Slow professor: Challenging the culture of speed in the academy. Toronto: Toronto University Press.

Cheung, A. B. L. (2012). How Hong Kong Universities balance the global and the regional. In B. Adamson, J. Nixon, \& F. Su (Eds.), The reorientation of higher education: Challenging the east-west dichotomy (pp. 95-112). Hong Kong: Springer/CERC The University of Hong Kong.

Clark, C. (2018). Time and power: Visions of history in German politics, from the thirty years' war to the third Reich. Princeton and oxford: Princeton University Press.

Gibbs, P. (Ed.). (2017). Transdisciplinary higher education and work-based learning: A theoretical basis revealed in practice. Cham/Dordrecht/Heidelberg/New York/London: Springer.

Gibbs, P., Ylijoki, O.-H., Guzmán-Valenzuela, C., \& Barnett, R. (Eds.). (2014). Universities in the flux of time: An exploration of time and temporality in university life. London: Routledge.

Head, S. (2011). The grim threat to British Universities. The New York Review of Books, 58(1), 58-64.

Hirschman, A. O. (1991). The rhetoric of reaction: Perversity, futility, jeopardy. Cambridge, MA/ London: The Belknap Press of Harvard University Press.

Judt, J. (2010). Postwar: A history of Europe since 1945. London: Vintage.

Lazerson, M. (2010). Higher education and the American dream: Success and its discontents. Budapest and New York: Central University Press.

Morris, W. (2004). In C. Wilmer (Ed.), News from nowhere and other writings. London: Penguin Books.

Nixon, J. (2008). Towards the virtuous university: The moral bases of academic practice. New York/London: Routledge.

Nixon, J. (2011). Higher education and the public good: Imagining the university. London/New York: Continuum.

Nixon, J. (2015). Inequality and the erosion of the public good. In O. Filippakou \& G. Williams (Eds.), Higher education as a public good: Critical perspectives on theory, policy and practice (pp. 163-177). New York: Peter Lang.

Rider, S. (2016). Science and speed addiction: The Scholar's vocation in the age of efficiency. Nordic Journal of Studies in Educational Policy, 2016(2-3).

Ritzen, J. (2010). A chance for European Universities. Or: Avoiding the looming university crisis in Europe. Amsterdam: Amsterdam University Press.

Scott, P. (2011, October 4). This enthusiasm for inequality will undermine us all. The Guardian, p. 33.

Sennett, R. (2012). Together: The rituals, pleasures and politics of cooperation. London: Penguin.

Universities, U. K. (2008). The changing academic profession in the UK and beyond. London: Universities UK.

Vostal, F. (2016). Accelerating academia: The changing structure of academic time. New York: Palgrave Macmillan.

Walton, J. K. (2011). The idea of the university. In M. Bailey \& D. Freedman (Eds.), The assault on Universities: A manifesto for resistance (pp. 15-26). London: Pluto Press.

Watermeyer, R. (2016). Impact in the REF: Issues and obstacles. Studies in Higher Education, 41(2), 199-214.

Watermeyer, R., \& Hedgecoe, A. (2016). Selling 'impact': Peer reviewer projections of what is needed and what counts in REF impact case studies. A retrospective analysis. Journal of Education Policy, 31(5), 651-665. 
Wilkinson, C. (2017). Evidencing impact: A case study of UK academic perspectives on evidencing research impact. Studies in Higher Education, 44(1), 72-85.

Williams, R. (1977). Marxism and literature. Oxford: Oxford University Press.

Wolin, S. S. (2010). Democracy incorporated: Managed democracy and the specter of inverted totalitarianism. Princeton and Oxford: Princeton University Press.

Zipin, L., \& Brennan, M. (2012). Governing the claims of global futures within Australian higher education. In B. Adamson, J. Nixon, \& F. Su (Eds.), The reorientation of higher education: Challenging the east-west dichotomy (pp. 247-268). Hong Kong: Springer/CERC The University of Hong Kong.

Open Access This chapter is licensed under the terms of the Creative Commons Attribution 4.0 International License (http://creativecommons.org/licenses/by/4.0/), which permits use, sharing, adaptation, distribution and reproduction in any medium or format, as long as you give appropriate credit to the original author(s) and the source, provide a link to the Creative Commons license and indicate if changes were made.

The images or other third party material in this chapter are included in the chapter's Creative Commons license, unless indicated otherwise in a credit line to the material. If material is not included in the chapter's Creative Commons license and your intended use is not permitted by statutory regulation or exceeds the permitted use, you will need to obtain permission directly from the copyright holder. 